\title{
Assessment of Past Rift valley Fever Outbreak Using Modeling, Risk Analysis and Decision Tree in Sudan
}

\author{
Mohamed E. Ahmed ${ }^{1 *}$, Tamador M. Abdellah ${ }^{1,2}$, Atif E. Abdelgadir ${ }^{3}$ \\ ${ }^{I}$ Central Veterinary Research Laboratory, Rift Valley fever unit, Sudan \\ ${ }^{2}$ Central Veterinary Research laboratory, Viral vaccine production department, Sudan \\ ${ }^{3}$ University of Khartoum, Faculty of Veterinary Medicine, Department of Preventive Veterinary preventive \\ medicine and public health, Sudan
}

*Corresponding Author: Mohammed Elsadig Ahmed Mansour, Central Veterinary Research Laboratory, Rift valley fever unit, P.O.Box 8067, Khartoum, Sudan.

\begin{abstract}
Background: A retrospective study was performed in selected states of the Sudan that include Gezira state, White Nile, Blue Nile, Khartoum, River Nile and Sennar states in order to determine the seroprevalence of Rift Valley Fever (RVF) and associated risk factors as well as an attempt was made to apply mapping, risk analysis tool to investigate the disease. Those epidemiological tools were used for purpose of good management strategies and policy makers as well. The source of data was epidemiological reports and archives from the Federal Ministry of Animal resources, universities and Non Governmental Organizations for outbreaks of RVF; also laboratory reports of serum samples tested by ELISA were considered. Thereafter, test performance characteristics of diagnostic sensitivity and diagnostic specificity were $99 \%$ respectively. A total of 3393from, sheep, goats and cattle were sampled and selected to be examined. Moreover, estimated seroprevalence of $R V F$ was $0.15 \%(n=905)$ in sheep, $0.20 \%(n=776)$ in goats and $0.13 \%(n=638)$ in cattle respectively. Also information gathered was used to determine the distribution of the disease, transmission and recovery rate of infection over point in time.
\end{abstract}

Method: This study was retrospective survey designed to investigate previous outbreaks of RVF. The method used was purposively to estimate risk analysis, modeling and decision tree to explain the distribution of the chronology of the disease.

Result: The current study was carried out quantitative and qualitatively report risk analysis to investigate $R V F$. Risk analysis revealed that RVF is likely to occur in the Sudan, providing that RVF in reported in Sudan and vaccination was estimated with highest rollback to reduce the seroprevalence of $R V F$ to be unlikely with expected value of \$ US 4368789. A frequency of $0.12 \%, 0.12 \%$ and $0.1 \%$ from cattle, goats and sheep population were entered in the SIR model, respectively. The adjustable parameters were susceptible, infected, recovery rate and death rate; the result was concluded that the curve of susceptible $(S)$ was declining, infected (I) was increasing; while recovered(R) was increasing. A total of 2487 mosquitoe was pooled, represented by 600 mosquitoes in the final model, recovery rate of mosquito overtime was 0.22 which is statistically not significant, $(P$-value $=0.9825)$, and rate of infection was $0.83 \%$. In the current study, the Basic reproductive number (RO) was estimated by one. Uncertainty for RVF model was ranged between 0.01 to 610.65 with confidence limit of $95 \%$. Thus, the study concluded that RVF is endemic in the Sudan; nonetheless, more evidence and information were needed for this epidemiological model.

Conclusion: Rift Valley Fever (RVF) is arthropod-borne viral zoonosis disease. It affects small ruminants, sheep and goats, and large ruminants like cattle and camel, and also can affect human. Rift Valley Fever virus (RVFV) belongs to the family Bunyviridae, genus Phlebovirus. The first isolation of RVFV was done in Kenya (4). RVFV is a negative sense RNA virus. RVFV genome is structured from three partites, small, medium and large $S$ segment is bidirectional open reading frame and its negative RNA abmisense that codes for Gn and Gs for glycoprotein of outer membrane of viral capsomere, M segment encodes for Non structural and structural protein of viral genome. It is peracute or acute febrile disease that is characterized by numerous abortions in female and high mortality among young animals and humans. Mosquitoe is the principle vector of the disease. It is transmitted by direct contact with infected tissues or organs of animals and ingestion of uncooked or row milk, the virus can transovarially transmitted from mother to fetus (1). The study was carried out to investigate the risk related to RVF seroepidemiology and distribution of the disease among livestock and to determine the most efficient policies in management of RVF outbreak by using retrospective data, however more further serosurveillances were required to thoroughly understand the epidemiology of the disease.

Keywords: $R V F$, disease modeling, risk analysis, decision tree, Sudan 


\section{INTRODUCTION}

Rift Valley Fever (RVF) is arthropod-borne viral zoonosis disease. It affects small ruminants, sheep and goats, and large ruminants like cattle and camel, and also can affect human. Rift Valley Fever virus (RVFV) belongs to the family Bunyviridae, genus Phlebovirus. The first isolation of RVFV was done in Kenya (4). RVFV is a negative sense RNA virus. It is peracute or acute febrile disease that is characterized by numerous abortions in female and high mortality among young animals and humans. Mosquitoe is the principle vector of the disease. It is transmitted by direct contact with infected tissues or organs of animals and ingestion of uncooked or row milk (1). Mortality and morbidity can reach from 5\% to $100 \%$ and case fatality rate could reach less than $1 \%$.

\subsection{Objectives}

This paper is to understand epidemiology of Rift Valley fever in the study by using Risk analysis tools.

\section{Materials AND Methods}

\subsection{RVF Statistical Model}

Statistical model was analyzed based on data and information given during RVF outbreak. Model for RVF was mathematical or compartment model which referred to $\mathrm{S}$ (susceptible), I (infected) and R (recovered) from the study population (figure 1). It is used to investigate the distribution of disease in the population. It has been built on SIR Model template adopted for influenza virus by (6). The parameters for host and vector models were obtained from literature (5),(15). The study assumed that population was homogenous. The model was comprised from a system of three coupled non-linear differential equations (Table 1 and 2).

$$
\begin{aligned}
& \dot{S}=\beta S I \\
& \dot{I}=\beta S I-\gamma I \\
& \dot{R}=\gamma I
\end{aligned}
$$

Where, $\dot{S}$ is susceptible, $\dot{I}$ is infected and $\dot{R}$ is recovered or and immunized individuals, $\beta$ is transmission rate, $\gamma$ is recovery rate and denote the derivatives with respective to time $t . N$ denotes for population size.

ARC Journal of Animal and Veterinary Sciences

$$
\begin{gathered}
N=S+I+R, \\
N=\dot{S}+\dot{I}+\dot{R}=0
\end{gathered}
$$

Applying phase plane analysis to the equation set

$$
\begin{gathered}
\dot{S}=\beta S I=0, \\
\text { and } \dot{I}=\beta S I-\gamma I=0
\end{gathered}
$$

Therefore, S-nullclines were

$$
\begin{aligned}
& S=0, \\
& I=0 ;
\end{aligned}
$$

and the I-nullclines were

$$
\begin{gathered}
S=\gamma \div \beta, \\
I=0
\end{gathered}
$$

The three nullclines form a triangle with vertices $(0,0),(N, O)$, and $(0, N)$ on the SI-plane. This triangle was invariant region of steady state. The trajectory always starts from the line $S+I=N$, since $R(0)=0$. A point was an equilibrium point if and only if $\dot{S}=\dot{I}=\dot{R}=0$, thus any trajectory was converge to a point $(S, 0)$ where $0 \leq S \leq N$.

If $S(0)=S 0<\gamma \div \beta$, both $S(t)$ ant $I(t)$ decreased and converged to a point on the $S$-axis; There is no outbreak. If $S 0>\gamma \div \beta$, I (t) first increased in the region $(\gamma \div \beta, I)$ and then decreased to 0 ; in this instance outbreak occurs. In conclusion, there was a threshold value $\gamma \div \beta$. Define as the basic reproduction number $(R 0)$.

$$
R 0=N \beta \div \gamma \approx S O \beta \div \gamma
$$

Then

$S 0>\gamma \div \beta \leftrightarrow R 0>1$,

and

$S 0<\gamma \div \beta \leftrightarrow R 0<1$,

If $R O<1, R V F$ epidemic dies out, when $R O>1$ a $R V F$ outbreak is possible, (17). The final model has been calculated by disease- euler-quad model which as follow

$\mathbf{R 0} *=r(n)+((1-d) * r * I(n)) * C+0.5((1-$

d) $*$ r*(k*S (n)*I (n)-r*I (n)))* $\mathrm{C}^{\wedge} 2$

Where, $\mathrm{s}(\mathrm{n})$ was susceptible, I(n) was infected, $\mathrm{r}(\mathrm{n})$ was recovered, $\mathrm{K}$ was transmission rate, $\mathrm{r}$ was recovery rate, $\mathrm{d}$ was death rate, $\mathrm{C}$ was constant 


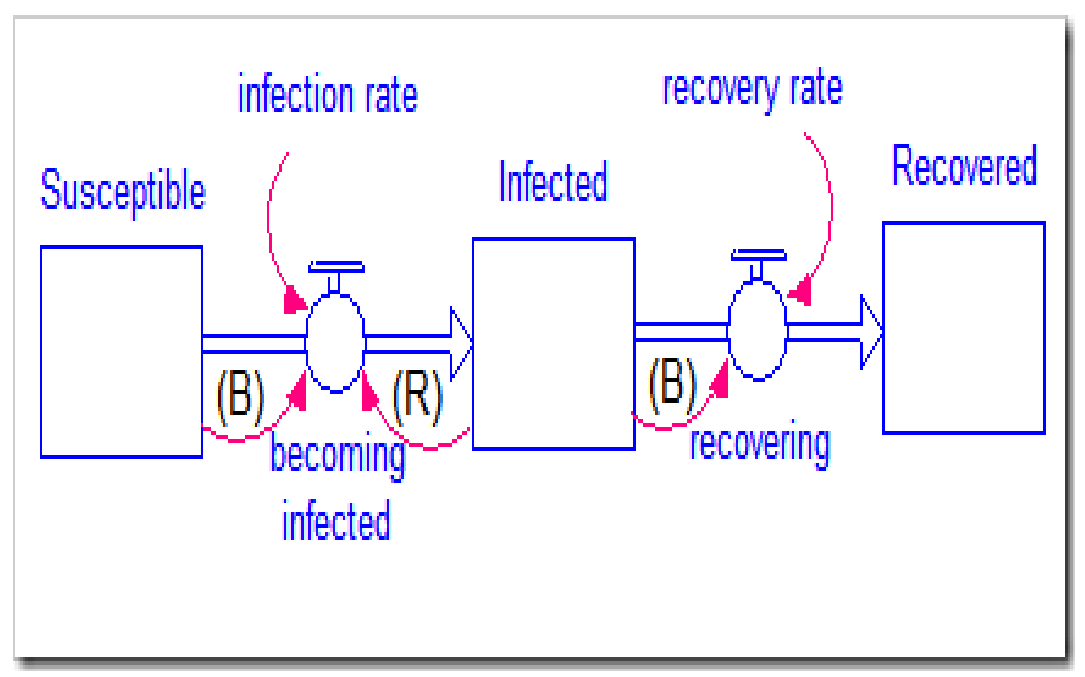

Figure1. SIR Model represents Susceptible, Infected and Recovered compartments of study population with infection and recovery rates. The explain the distribution of $R V F$ among study population by dividing it into three parts

Table1. Adjustable parameters of Rift Valley Fever model in ruminant

\begin{tabular}{|c|l|c|c|c|}
\hline Parameter* (adjusted ) & \multicolumn{1}{|c|}{ Description } & Symbol & Value & Reference \\
\hline Susceptible & $\begin{array}{l}\text { Susceptible with RVF from animal } \\
\text { sampled }\end{array}$ & (S0) & 49990 & Estimated \\
\hline Infected & Infected with RVF from animal sampled & (I0) & 10 & Estimated \\
\hline Total in population & population of study (ruminant) & $(\mathrm{N})$ & 50000 & Estimated \\
\hline Transmission rate & Transmission rate of RVF from S0 to I0 & $(\mathrm{k})$ & 0.000004 & Estimated \\
\hline Recovery rate & Recovery duration (year) & $(\mathrm{R})$ & $8 / 365$ & $(16)$ \\
\hline Death rate & Natural death rate in ruminant(year ${ }^{-1}$ ) & $(\mathrm{d})$ & $1 / 5.7$ & $(18)$ \\
\hline Total sick \&not died & & (Rfinal) & 16500 & Estimated \\
\hline Total deaths & & (Tfinal) & 15000 & Estimated \\
\hline Number never sick & & (Sfinal) & 33500 & Estimated \\
\hline Max sick at one time & & (Imax) & 7000 & Estimated \\
\hline Max prop(of S0)sick & & (ofS0) & 0.140028 & Estimated \\
\hline $\begin{array}{c}\text { Max prop(of N)sick } \\
\text { Mosquito infection rate }\end{array}$ & $\begin{array}{l}\text { Probability of infection in ruminants } \\
\text { Proportion of infected mosquitoes from } \\
\text { vertical transmission }\end{array}$ & (ofN) & 0.14 & (19) \\
\hline
\end{tabular}

*Parameters entered in SIR model were adjusted from different publications to understand the proportion of Suspected, Infected and Recovered livestock in relation to RVF. Also, it is estimated when there is no reference cited. These parameters were used to calculate the model to investigate the distribution of RVF among study population.

Table2. Adjusted parameter for RVF vector model

\begin{tabular}{|c|c|c|c|c|}
\hline Parameter* (adjusted ) & Description & Symbol & Value & Reference \\
\hline Mosquito infection rate & $\begin{array}{l}\text { Proportion of infected mosquito } \\
\text { from vertical transmission }\end{array}$ & (k) & 0.000005 & $(20)$ \\
\hline Recovery rate & $\begin{array}{l}\text { Mosquito recovery rate from RVF } \\
\text { infection }\end{array}$ & (r) & 0.021918 & Estimated \\
\hline Death rate & Death rate of mosquito due RVF & (d) & 63.84 & $(21)$ \\
\hline Susceptible & $\begin{array}{l}\text { RVF susceptible mosquito } \\
\text { population }\end{array}$ & (S0) & 59990 & Estimated \\
\hline Infected & $\begin{array}{l}\text { Infected population of mosquitoes } \\
\text { by RVF }\end{array}$ & $(\mathrm{I} 0)$ & 10 & Estimated \\
\hline Total population & Total population of mosquitoes & $(\mathrm{N})$ & 2487 & Estimated \\
\hline
\end{tabular}

This parameter were used to calculate the model for Mosquitoe vector and understand the distribution and circulation of the virus among vector of the disease, and can be used to generate models for infectious disease. 
Assessment of Past Rift valley Fever Outbreak Using Modeling, Risk Analysis and Decision Tree in Sudan

Table3. Rift Valley Fever risk groups and risk assessment and management

\begin{tabular}{|c|c|c|c|c|}
\hline RVF Risk group & \multicolumn{3}{|c|}{ RVF (risk assessment \&management) } & \\
\hline Risk & Likelihood & Impact & Risk score & Treatment/action \\
\hline $\begin{array}{l}\text { RVF incidence (index } \\
\text { case) }\end{array}$ & $\begin{array}{l}33.3 \% \text { probability } \\
\text { to produce } \\
\text { secondary case }\end{array}$ & $\begin{array}{l}\text { Presence of IgM } \\
\text { Abs in free area }\end{array}$ & $\begin{array}{l}\text { Acceptable level of } \\
\text { risk e.g. development } \\
\text { of a RVF foci }\end{array}$ & $\begin{array}{l}\text { Treatment of infected } \\
\text { cases or and / quarantine } \\
\text { of index case }\end{array}$ \\
\hline RVF foci & $\begin{array}{l}33.3 \% \text { probability } \\
\text { to produce an } \\
\text { outbreak }\end{array}$ & $\begin{array}{l}\text { Presence of } \\
\text { IgM\&IgG Abs } \\
\text { in endemic area }\end{array}$ & $\begin{array}{l}\text { Unacceptable level of } \\
\text { risk e.g. } \\
\text { development of RVF } \\
\text { outbreak } \\
\end{array}$ & $\begin{array}{l}\text { Buffer vaccination } \\
\text { around a foci or/ and } \\
\text { restricted movement }\end{array}$ \\
\hline RVF outbreak & $\begin{array}{l}33.3 \% \text { probability } \\
\text { to produce a } \\
\text { pandemic }\end{array}$ & $\begin{array}{l}\text { Presensce of } \\
\operatorname{IgM} \& \operatorname{IgG} \text { Abs } \\
\text { both in free and } \\
\text { endemic areas }\end{array}$ & $\begin{array}{l}\text { Unacceptable level of } \\
\text { risk e.g. spread of } \\
\text { RVF through trade } \\
\text { route }\end{array}$ & $\begin{array}{l}\text { Official notification \& } \\
\text { reporting of disease } \\
\text { status, vaccination, } \\
\text { vector control, } \\
\text { quarantine and trade ban }\end{array}$ \\
\hline
\end{tabular}

\subsection{Statistical Analysis}

Mathematical or statistical model was adopted by using the SIR model used in Microsoft Excel, version 2007 and Decision tree were analyzed by Solution tree version.

\section{Results}

\subsection{SIR Model in Host}

A total of 50000 hosts were entered in the SIR model over time, to explain the trend of the disease. Population structure was $58.8 \%$ susceptible, $3.9 \%$ infected and $37.3 \%$ recovered. The model was found that at $0.18 \%$ of the herd seroprevalence of sheep flocks has shown only one positive case could be detected in order to consider that the herd was positive for RVF, While at $0.56 \%$ herd seroprevalence of goat flocks only one positive case could be detected in order to consider that the herd was positive for RVF and at $0.73 \%$ herd seroprevalence of cattle only one positive case could be detected in order to consider the herd was positive for Rift Valley Fever (Figure 2, 3 and 4).

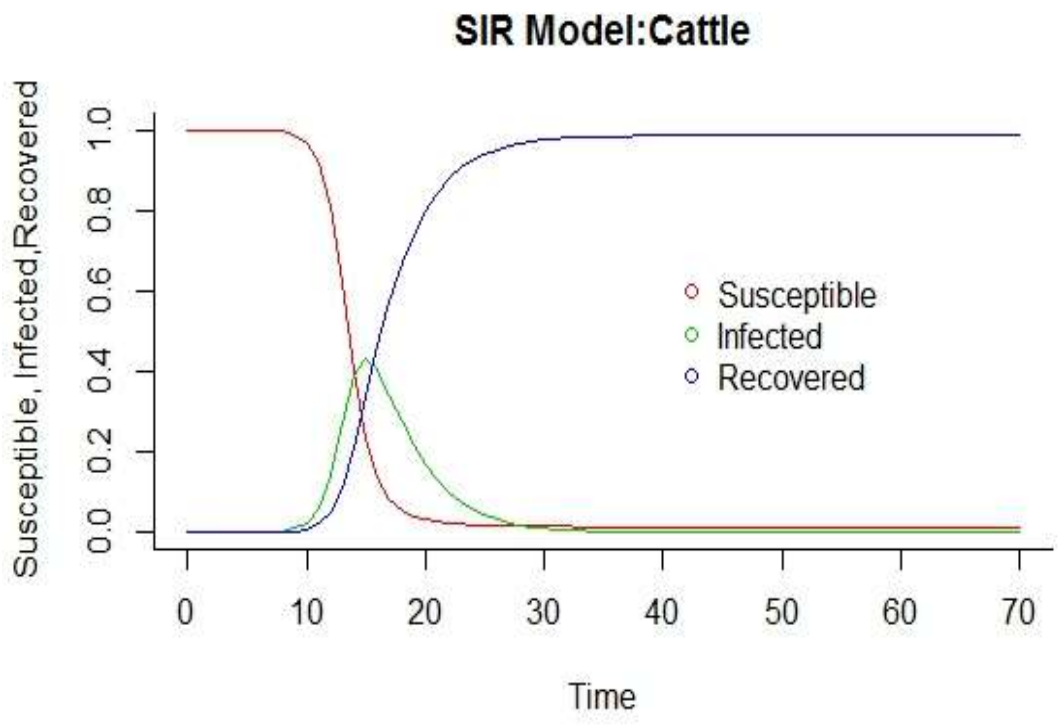

Figure2. SIR Model for RVF in Cattle population in Sudan from 1973 to 2007

SIR Model is referred to as suspected(S) was decreasing at 95 individual, infected(I) was increasing at 80 individual and Recovered(R) was in increasing with continuous growth at
200 individual with 100 times (iteration) multiplication. Also this to explain the distribution and trend of RVF in population by dividing it three parts. 


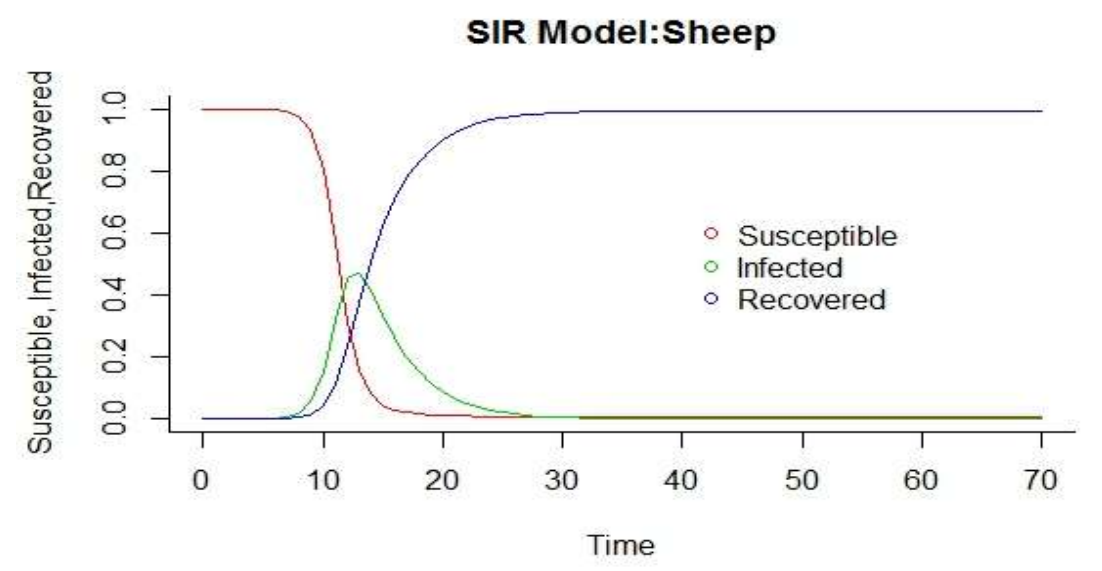

Figure3. SIR Model for RVF in sheep population in Sudan from 1973 to 2007

SIR Model is referred to as suspected(S) was decreasing at 90 individual, infected (I) was increasing at 85 individual and Recovered (R) in increasing at 195 at 100 time (iteration) multiplication. This was development of point curve of RVF, when it occurred at point in time. The figure was illustrating the Susceptible, Infected and Recoved model for Rift Valley fever in animal population over time and their percentages were $58.8 \%, 3.9 \%$ and $37.3 \%$ respectively. This means to simulate the rate of occurrence of RVF to understand the occurrence in real life. Also this to explain the distribution and trend of RVF in population by dividing it to three parts.

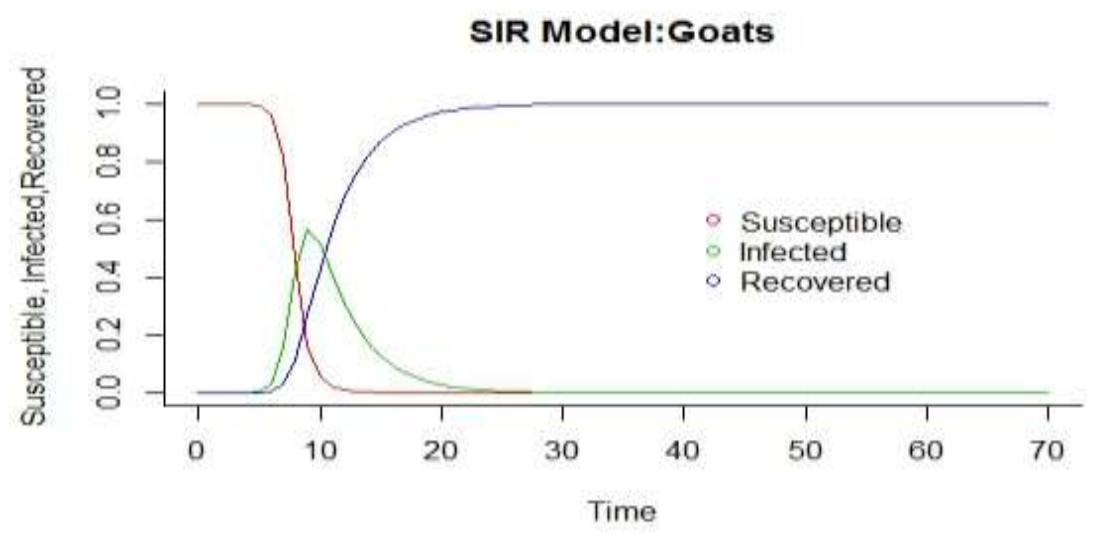

Figure4. SIR Model for RVF in goat's population in Sudan from 1973 to 2007

SIR model is referred to as Susceptible, Infected and Recovered for goats population. Susceptible was decreasing, infected was increasing and Recovered was increasing for 70 days. It represents the basic SIR model for an epidemic at a time. Also this to explain the distribution and trend of RVF in population by dividing it into three parts.

A $0.12 \%$ of cattle populations were enforced in the model. The adjustable parameters for the final model were 49990 susceptible, 10 infected for 50,000 animal hosts, 0.000004 was transmission rate, 0.021918 was recovery rate and 0.3 death rate. The curve of susceptible population were declining at 500000 , curve for infected were increasing and reached the peak at 30500 , while recovered had gotten plateau at 40000 (Figure2). The sheep populations were 50390000 , and the goat populations were 42756000 with density of 20.11 and 17.06 respectively. A 0.1 and $0.12 \%$ from sheep and goats were entered in RVF Model, respectively. The parameters were a susceptible (S0), 49990susceptible, 10 infected for50000, 0.000004 transmission rates, 0.02 recovery rates and 0.03 death rates. The curve for susceptible sheep and goat were declining at 30500, curve for infected were reached 20500, whereas recover get plateau at 50000 (Figure 3and 4). 


\subsection{Vector Model}

This study had revealed that Mosquito as a principle vector to transmit RVF in the Sudan, Aedes spp was a primary vector to cause RVF according to its biology which renders RVFV to survive for longer period during dry season in Dambos "land depression". This feature (transovarian transmission) was to preserve RVFV in mosquito's egg; when flooding comes, infected eggs hatch and flare up and disseminate RVFV to susceptible population depending on mosquitoes vector density. Culexs pp has found to have a secondary role in transmission of RVFV in the Study area from 1973 to 2007 (Table 2).

A total of 60000 sample of mosquitoes were entered in SIR model after pooling with $95 \%$ confidence limit (CL), transmission rate was 0.000005 , death rate was $63.8 \%$ and RVF recovery rate of mosquito was 0.02 (Figure 5), (Table4).

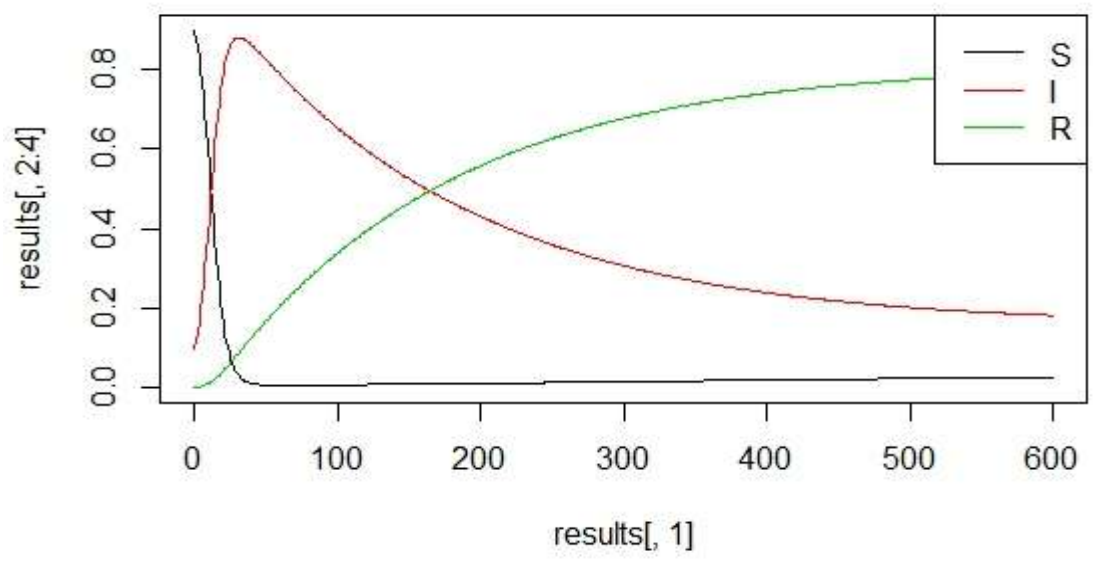

Figure5. Vector model

Vector Model is referred to suspected (s) is decreasing at 30 individual, infected(I) was increasing at 50 individual and recovered (R) was increasing at 95 individual with 100 time iteration. This was development of epidemic curve in vector at a point in time. This to explain distribution of RVFV in mosquitoe vector population by dividing it into three parts.

Table4. Identification of RVF mosquito vectors in Sudan from 1973 to 2007

\begin{tabular}{|l|l|l|c|}
\hline Country & RVF outbreak & Vector & Reference \\
\hline Sudan & 1973 & Culexspp, Aedesspp & $(25),(26)$ \\
\hline & 1997 to 1998 & Not defined & $(27),(28)$ \\
\hline & 2003 to 2006 & Not defined & $(27)(28)$ \\
\hline & 2007 to 2008 & Aedesspp, culexspp & $(29),(30)$ \\
\hline
\end{tabular}

*Parameters entered in Vector Model were adjusted from different publications to understand the proportion of Suspected, Infected and Recovered Mosquito vector in relation to RVF. Also, it is estimated when there is no reference cited.

\subsection{Decision Tree Model}

The current study has built model for RVF control measures by solution tree with 21 nodes, total probability of $31 \%$ and expected value of $\$$ $78,774,726.09$. Four decision branches, sixteen chance branches and twelve end points had been produced. Assumptions for the scenario had been analyzed with $0.5 \%$ Probability or likelihood distribution with $95 \%$ confidence. The expected or pay off value of vaccination, vector control and expert opinions were estimated by $\$ 78,774,726, \quad \$ 7,217,056$ and $\$ 24,056,798$, respectively. The model has resulted in $37.5 \%$ chance of success for vaccination, whereas vector control and expert opinion have $18.75 \%$ chance of success as countermeasures for RVF outbreak. Vaccination was estimated with highest rollback value of $\$ 69,900,624$. It has resulted in decreasing of RVF prevalence to be unlikely or negligible with expected value of $\$ 4368789$ (Figure 6). 
Assessment of Past Rift valley Fever Outbreak Using Modeling, Risk Analysis and Decision Tree in Sudan

\begin{tabular}{|c|c|c|}
\hline SolutionTree & & \\
\hline New Decisicn Tree & Noder: & $'$ \\
\hline Date:7]/201513450:M & Totput: & ' 311 \\
\hline Bruser & Eptale: & ' 78,77476609 \\
\hline
\end{tabular}

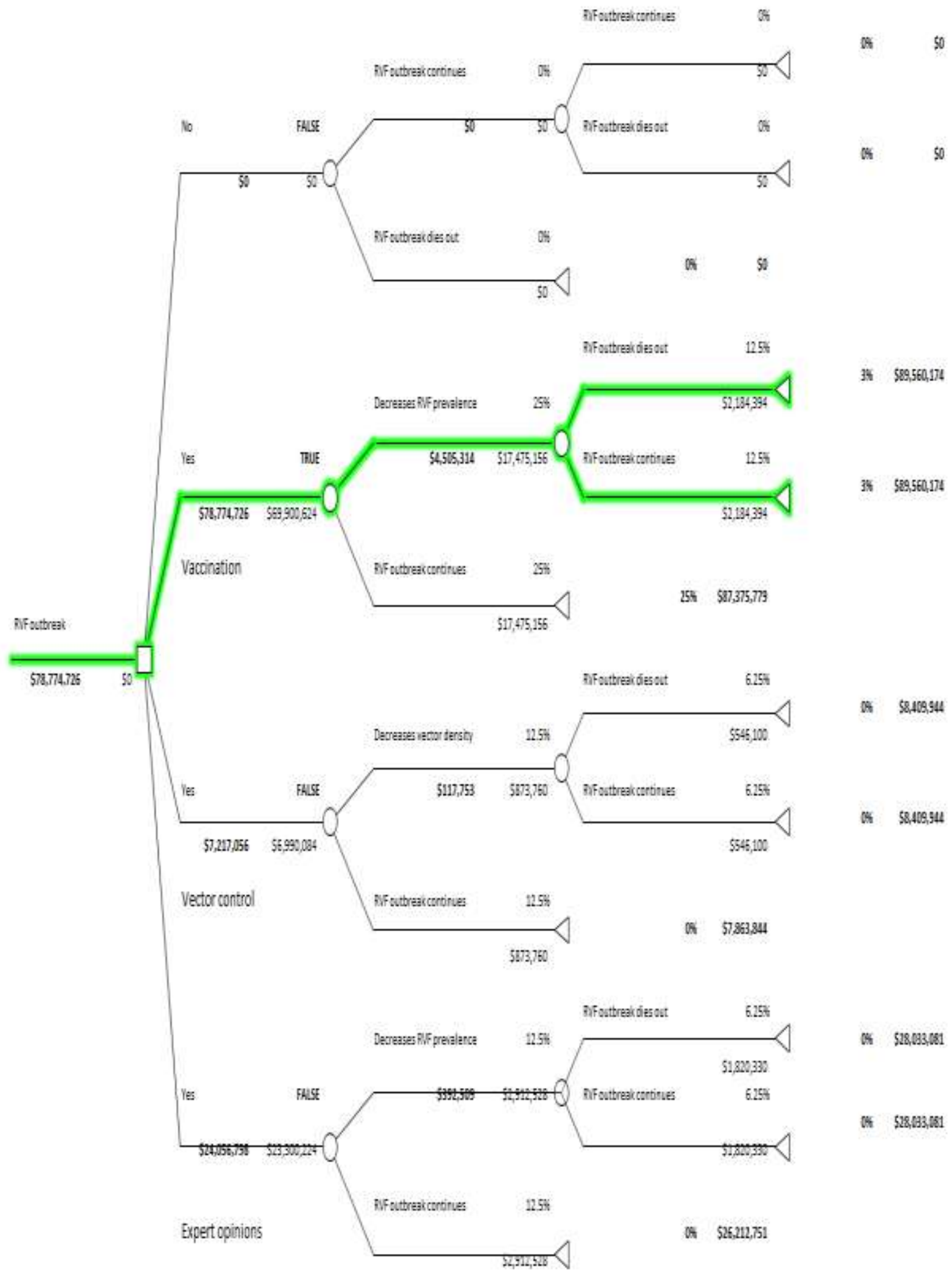

Figure6. Decision tree model for RVF outbreak explaining probability and expected values of branches and cost-effectiveness for RVF control 
Decision tree has explained the probability distribution from the nodes and branches of decision analysis of three options to control RVF which are vaccination, vector control and expert opinions to estimate what is more rational path to be considered. This method is one of the decision supporting tools that have role in policy for prevention and control of infectious diseases. This diagram explains also the percentage of most important tool for control of RVF with less economic cost.

\subsection{Uncertainty Analysis of RVF Model}

Uncertainty was analyzed to estimate the fitness of RVF model with $95 \%$ confidence interval (CI) to simulate the occurrence of the disease in the real life. Uncertainty for RVF Model was ranged between 0.01 to 610.65 with confidence of $95 \%$. Five parameters were entered and analyzed in the model for sheep, goats, cattle and vector. Uncertainty for average of contact were 124.65, susceptiblewas610.65, infected were 401.94, while uncertainty for duration of infectionness was 0.72. Lower quantile for susceptible, infected, transmissibility, rate of contact and duration of infectionness were estimated by $152.6,100.4,0.002,31.1,0.18$, while upper quantile were estimated by 457.9 , 301.4, 0.006, 93.4 and 0.54 respectively. Also, uncertainty was estimated by measuring homogeneity and representativeness, of parameters taken against day of time (Figure 7).

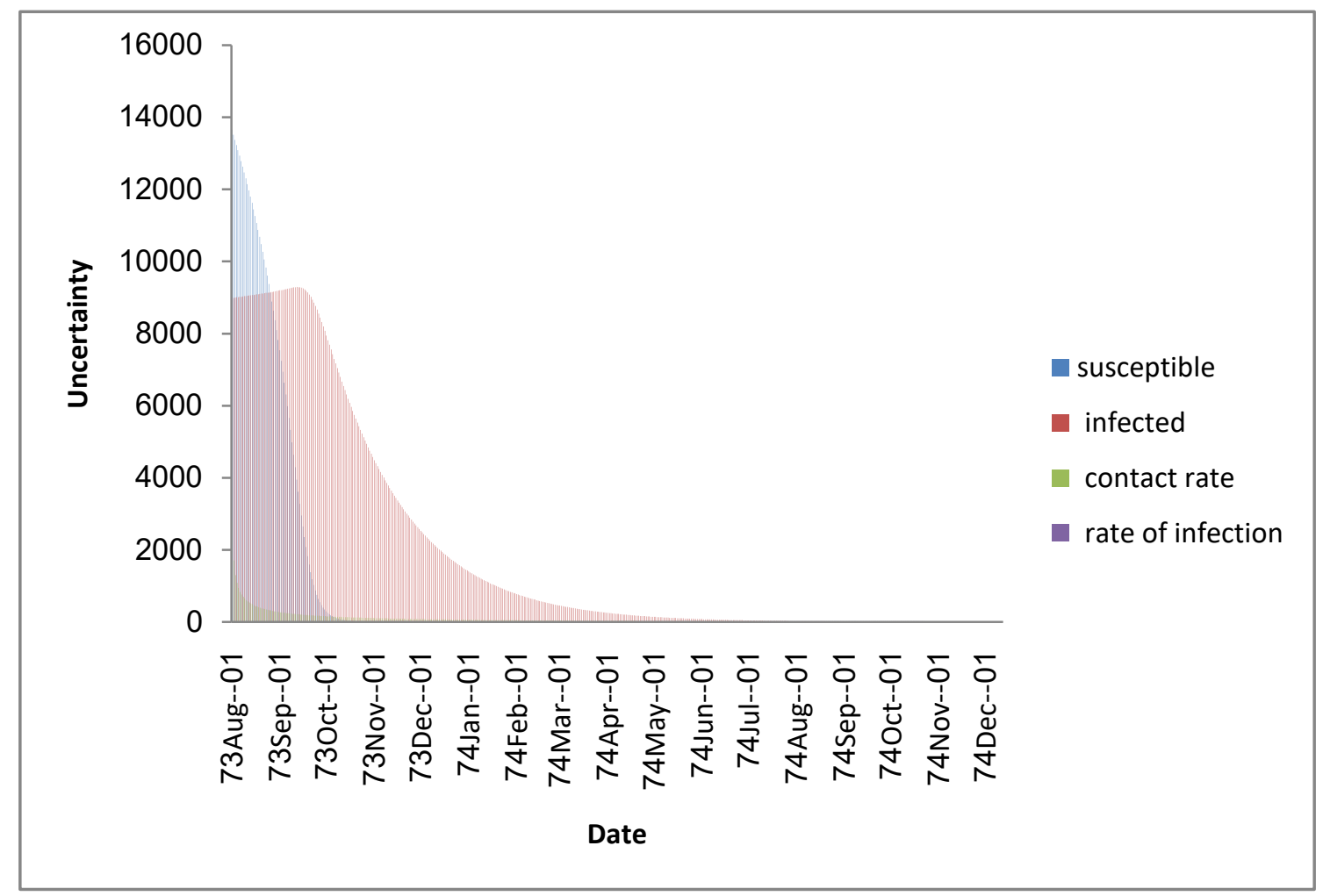

Figure7. Uncertainty analysis for SIR model

Uncertainty was obtained by estimating the standard error (SE) of sample (SE mean was 26.6 for suspected, 139.3 for rate of contact and 0.15 for duration of infectionness) with $95 \%$ confidence interval. It was measuring the degree of goodness of fit for the model with optimization of assumed parameters to be simulated at SIR model. This analysis is to investigate the accuracy of disease model that has be studies in this research.

\section{DISCUSSION}

In this study, the SIR Model had analyzed dynamic and epidemiology of RVF in study population. The populations at risk were estimated over 30,000 heads for sheep, goat and cattle, whereas study host was more exposed to RVFV (Figure 2,3and 4), with uncertainty analysis that ranges from 0.01 to 610.65 , with confidence of $95 \%$, although there is lack of information and data available for the disease during study, which is important to know the dynamics of the disease when it occurs. Clustering had been reported in Gizera state, where foci or pockets of the disease were present; this had come into agreement with research done by (8), where clustering can estimate the incidence and risk assessment of 
RVF in study area for a certain period of time which provides understanding for the spatial distribution and epidemiology of RVF (table 3). Frequency of annual temperature and annual rain fall were been analyzed to understand its relatioship with RVF outbreaks in study area.Environmental risk factors like ElNioSouthern Oscilliation, Average Annual precipitation and Elevation Map had significant and important role to play as predisposing factors to occurrence of RVF by increasing of rainfall which improve multiplication of $\mathrm{RVF}$ insect vectors to dissemenate the virus to susceptible hosts. Studying the climate and ecosystem, RVF was found to be correlated with weather anamolies and Elino phenomenon in Eastern Africa by (22), which was leading to upaverage rainfalls that prefer replication and increased mosquito density. This has important role in tramission cycle of RVFV to exposed host, when the virus can survive in egg of pregnant mosquites which could be dormant in dambos or land depression for long peroid of time specially in interepidemic peroid and when rainfall come, it flared up and dissmenated the virus to suspected hosts, this is has been significantly important observation in East of Africa . Also, it had explained that parameters of deterministic models (2) is analyzing the multiplication rate of the disease and rate of infection in a given geographical zone.Vector model had analyzed more than $80 \%$ of mosquito to carry RVFV to the vector, given that susceptible hosts were exposed to the vector, RVF outbreak is likely to occur with $95 \%$ confidence. In addition, entomological survey had shown that Aedes vexans and Culex quinquefasciatus were positive to RVF virus (13).Therefore, epidemiological model for RVF in this study was carried out analysis of SIR model, vector model, spatial mapping model and risk factors associated with RVF seroprevalence. Epidemiological model for this study had manifested probability distribution of RVF on study population and different degree of statistical differences and association for host population, environmental risk factors with RVF seroprevalence, this agreed with the effect of environmental risk factors and disease dynamics on population by(23), whereas models is build up on availability of information and report about the disease; Although it is also important to improve the knowledge about disease by analyzing available information by using disease models. RVF is mainly endemic in Africa and these are involving several regions and countries in the same time. Also, it had occurred outside African continent in Arabian Peninsula and some Indian Ocean islands. It was associated with periodic cycle and heavy rain falls and flooding which usually occurred after interval which prefers mosquito proliferation. RVFV was first reported in Sub-Saharan Africa and southern Africa (3).Although the virus had been found outside Sub-Saharan Africa to Egypt (Gerdes,2004), Saudi Arabia and Yemen (24). In 1973, RVF outbreak was erupted in Southern Africa where human deaths were reported (12). A 958 human causalities in1977 and 200 human deaths in 1978 were occurred due RVF epidemic in Egypt. In Kenya and Somalia, RVF caused 478 human deaths in 1997(14). In 2000, RVF outbreak was confirmed in Saudi Arabia and Yemen with 882 confirmed cases and 124 deaths (11). In the Sudan, serological evidence of RVF was reported in 1936 which revealed $6.7 \%$ of 164 human sera by using precipitating antibodies (7). In addition, reporting of cases of $\mathrm{RVF}$, diagnosis and treatment capability and raising awareness of the disease epidemiology, training of medical cadres and research and development is importantly significant to exceed the planning and policy to contingency and preparedness against RVF and reducing its spreading in suspected countries.

\section{CONClusion}

Rift Valley Fever (RVF) is arthropod-borne viral zoonosis disease. It affects small ruminants, sheep and goats, and large ruminants like cattle and camel, and also can affect human. Rift Valley Fever virus (RVFV) belongs to the family Bunyviridae, genus Phlebovirus. The first isolation of RVFV was done in Kenya (4). RVFV is a negative sense RNA virus. RVFV genome is structured from three partites, small, medium and large. It is peracute or acute febrile disease that is characterized by numerous abortions in female and high mortality among young animals and humans. Mosquitoe is the principle vector of the disease. It is transmitted by direct contact with infected tissues or organs of animals and ingestion of uncooked or row milk (1). The study was carried out to investigate the risk related to RVF seroepidemiology and distribution of the disease among livestock and to determine the most efficient policies in management of RVF outbreak by using retrospective data, however more further serosurveillances were required to thoroughly understand the epidemiology of the disease. 
Abbreviation

CDC center of Disease control

CI confidence interval

CL confidence limit

ELISA Enzyme Linked Immunosorbent assay

R0 Basic Reproduction number

RNA Ribonucleic acid

RVF Rift Valley Fever

RVFV Rift Valley Fever Virus

SIR Suspected, infected and recovered

\section{Declaration}

This to declare that this research work is to fulfill partial requirement of doctoral degree

\section{Ethical Approval and Consent to participate}

It is not in human data (retrospectively registered)

\section{A Statement to Confirm that all Methods were Carried out in Accordance with Relevant Guidelines and Regulations.}

This research work has been carried out with accordance and guidelines and regulation of Central Veterinary Research Laboratory, Sudan in order to fulfill a partial requirement of Phd degree on preventive veterinary medicine and public health, nature of the research study in retrospective registered data gathered and collected with multistage cluster sampling from records and laboratory results of serum sample of livestock representing study area.

\section{A Statement to Confirm that all} Experimental Protocols were Approved by a Named Institutional and/or Licensing Committee

The current research work has been done and approved by regulation and guidance of research institution of university of Khartoum, college of graduate studies in Agriculture and Veterinary medicine and Central Veterinary Research Laboratory, sudan Where student is working and has got approved from director of Central Veterinary Research Laboratory and research institution at the university to conduct his research work accordingly.

\section{Consent for Publication}

All authors have agreed to publish this manuscript

\section{Availability of data and materials}

Yes

\section{Competing Interests}

There is no conflict of interest from any of authors of this manuscript

ARC Journal of Animal and Veterinary Sciences

\section{Funding}

Ministry of science and Technology had been chosen as funder from the list Authors' Contributions

The manuscript is written and statistically analyzed by Mohammed E.Ahmed ${ }^{1}$, the bench work and data availability for project was supplied by Tamador M. Abdellah ${ }^{1,2}$ The manuscript was revision and designed for writing by, Atif A Abdelgadir ${ }^{3}$

\section{ACKNOWLEDGEMENT}

The authors are thoughtful for the Director of Central veterinary Research Laboratory for permission to publish this research article.

\section{REFERENCES}

[1] Adam, A.. Manifestations of severe Rift Valley Fever in Sudan. Int .J. infect. Dis, (14): 179180 (2010).

[2] Chalom,A and Prado,p. Uncertainty analysis and composite hypothesis under the likelihood paradigm,. Q-bio.QM(2015) .

[3] Daubney , R., Hudson J.R., Gamham P.C.. Enzootic hepatitis or Rift Valley Fever.An undescribed virus disease of sheep, cattle and man from East Africa. J. Pathol. Bacteriol , (34): 545-579 (1931).

[4] Daubney R., Hudson J.R.. Rift Valley Fever.The Lancet J, (1): 611-612 (1932).

[5] Farida Chamchod., Robert Stephen Cantrell., Chris Cosner., Ali N Hassan., John C.Beier., Shigui Ruan. A modeling approach to investigate Epizootic outbreaks and Enzootic Maintenance of Rift Valley Fever virus. Bull Math Biol (76):2052-2072(2014).

[6] Findlater, A. http://archives.aidanfindlater.com/blog/2010/0 4/20/the-basic-sir-model-in-r/. Retrieved 518 , 2018, from http://rstudio-pubsstatic.s3.amazonaws.com/ 6852_c59c5a2e8ea3456abbeb017185de603e.html.

[7] Findlay, G., Stefanopoulo, G. J., \& Maccalum, F. O.. Presence d'anticorps contre la fievre de la Valle du Rift dans le sang des Africans. Bull .soc. Pathol. Exot , (29):986-996 (1936).

[8] Gadha, S.. A retrospective analysis of the epidemiology of Rift Valley Fever in Namibia. dissertation submitted to the Department of Veterinary Tropical Disease, Faculty of Veterinary Science University of Pretoria in Partial fulfillment of the requirement for degree of Msc (Animal/Human/Ecosystem Health) (2015).

[9] Gerdes, G.. Rift Valley Fever. Rev.Sci.tech.Off.int.Epiz, 23 (2): 613-623 (2004). 
[10] Matthew, J. K and Pejman, R. Modeling InfectiousDiseases in Humans and Animals. Princeton University Press. (2008).

[11] Mohamed A., A.M. Ashshi, A.H. Asghar., I.H.A. Abd El-Rahim., A.G. El-Shemi \& T.Zafar. Seroepidemiological survey on Rift Valley fever among small ruminants and their close human contacts in Makkah., Saudi Arabia, in. Rev.Sci.tech.Off.int.Epiz 2014, (3):33(2011).

[12] Peters, C.J and Linthicum, k.L. Handbook of Zoonoses. ( $2^{\text {nd }}$ edition) CRC Press(1994).

[13] Rania, A., Emadeldin, H. K., El Amin, E. R.. Rift Valley Fever Virus (RVFv) Dissemination inside Mosquitoes and Investigation of the Influence of Climate on Mosquitoes Abundance. J. Entomol. Zool. Stud, 1 (5): 1-9 (2013)

[14] WHO. Rift Valley Fever outbreak in East Africa. Atlanta, USA: International Conference on Emerging Infectious Disease(1998).

[15] Linthicum K., Davies F.G, Kairo A., Bailey C. . Rift Valley Fever virus( family Bunyaviridae, genus Phlebovirus). Isolations from Diptera collected during an inter-epizootic peroid in Kenya. J Hyg , (95): 197(1985).

[16] Pepin, M ., Bouloy, M., Bird ,B.H, Kemp A., Paweska J.. Rift Valley Fever virus (Bunyaviridae:Phlebovirus): an update on pathogensis, molecular epidemiology, vectors, diagnostics and prevention. Vet. Res 2010, (61): 41(2010).

[17] Diekmann, O \& Heesterbeek, J.A.P.. Mathematical epidemiology of infectious diseases: Model. New York:John Wiley \& Sons, Ltd. (2000).

[18] Majok, M , Zessin, K. H., Baumann, M. PO.. Analyses of baseline survey data on rinderpest in Bahr elGhazal Province, with proposal of an improved vaccination strategy against rinderpest for southern Sudan. Trop Anim Health Prod ,1991 (23): 186-196(1991).

[19] Turell, M., Linthicum KJ., Patrican, L.A., Davies, F G., Kairo, A, Bailey, C I.. Vector competence of selected African mosquito (Diptera:Culicidae) species for Rift Valley Fever virus. J Med Entomol, (45): 102-108 (2008).
[20] Freier, J and Rosen, L.. Vertical transmission of dengue virus by the mosquitoes of the Aedes scutellaris group. Am J.Trop. Med. Hyg, (37): 640-647 (2014).

[21] Mpeshe, S.C., Haario, H., Tchuenche, JM.. A mathematical model of Rift Valley Fever with human host. Acta. Biotheo, (59): 231-250 (2011).

[22] Claudia Mroz, Mayada Gwida, Maged ElAshker, Mohamed El-Diasty, Mohamed ElBeskawy, Ute Ziegler, Martin Eiden, and Martin H. Groschup.. Seroprevalence of Rift Valley fever virus in livestock during interepidemic period in Egypt, 2014/15. BMC Vet Res., (87) :13 (2017).

[23] Matthew, J. K and Pejman, R.. Modeling Infectious Diseases in Humans and Animals. Princeton University Press(2008).

[24] Jupp., kemp,A., Grobbelaar,A. The 2000 epidemic of RiftValleyfever in Saudi Arabia: Mosquitoe vector studies. Med Vet entomol, (16): 245-52 (2000).

[25] Imadeldin .A, Bobbie R. Erickson., Rehab M Elageb., Marina L., Khristova, Serena A., Carroll., Isam M. Elkhidir., Mubarak E.Karsany., Abdelrahim EKarrar., Mustafa I Elbashir and Stuart T.Nichol.. Rift Valley Fever, Sudan ,2007 and 2010. Emeg Infect Dis , (19): 246-253 (2013).

[26] Kowther Mohamed Saeed Ahmed., Amna Ahmed Hamid., Abbas Doka.. Investigation of Spatial risk factors for RVF disease occurrence using remote sensing \& GIS -A case study: Sinnar state, Sudan. Journal of Geopraphic Information System , (7): 226-257 (2015).

[27] CDC. Rift Valley Fever outbreak-Kenya, November 2006-January2007. MMWR Morb Mortal Wkly Rep, pp. 56-73 (2007).

[28] Yousif, E . H., Eliningaya, J .K., Mostafa, M. M., El Amin, E.R and Johnson, O.O. Recent outbreak of Rift Valley Fever in East Africa and the Middle East. f.p.u.b.h (169). :2 (2014).

[29] Wilson, W.. Rift Valley Fever viurs ecology and the epidemiology of disease emergence. Ann N Y Acad, 169-180 (1994).

[30] Osama, A., Clas, A., Rosemary, S., and Magnus, E.. The 2007 Rift Valley Fever outbreak in Sudan. PloS. Negl. Trop. Dis, 5 (9), $1229(2011)$

Citation: Mohamed E. Ahmed, Tamador M. Abdellah, Atif E. Abdelgadir. Assessment of Past Rift valley Fever Outbreak Using Modeling, Risk Analysis and Decision Tree in Sudan. ARC Journal of Animal and Veterinary Sciences. 2020; 6(2):1-11. DOI: https://doi.org/10.20431/2455-2518.0602001.

Copyright: (C) 2020 Authors. This is an open-access article distributed under the terms of the Creative Commons Attribution License, which permits unrestricted use, distribution, and reproduction in any medium, provided the original author and source are credited. 